\title{
Effects of Spangle Size on Performances of Hot-dip 55\%Al-Zn Alloy Coating
}

\author{
Taixiong Guo ${ }^{1,2, *}$, Changsheng Liu ${ }^{1}$, Changrong Ran ${ }^{2}$, Xueqiang Dong ${ }^{2}$ \\ ${ }^{1}$ School of Materials Science and Engineering, Northeastern University, Shengyang 110819, Liaoning, \\ China \\ ${ }^{2}$ Pangang Group Research Institute Co. Ltd., Panzhihua 617000, Sichuan, China \\ *E-mail: guotaixiong@126.com
}

doi: $10.20964 / 2018.10 .07$

Received: 7 April 2018 / Accepted: 7 June 2018 / Published: 1 September 2018

\begin{abstract}
The influences of spangle on corrosion resistance, formability and paintability of hot-dip $55 \% \mathrm{Al}-\mathrm{Zn}$ alloy coating (GL) steel sheet are the main concern for household appliance manufacturers. In this study, the effects of spangle size on those performances of GL steel sheet were investigated through electrochemistry, neutral salt spray, bending and Erichsen cupping, and electrostatic powder spraying tests. The microstructure and surface morphology of the samples were analyzed by scanning electron microscopy (SEM), atomic force microscopy (AFM), nano indentation, surface roughometer and glossmeter. The influencing mechanisms of spangle size were also discussed. The results showed that decreasing the spangle size refined Al-rich dendrites, reduced dendrite spacing, and segregated Zn-rich phase. This, in turn, improved both the corrosion resistance and formability of the coatings. The electrostatic powder spraying tests confirmed the good paintability of all samples with different spangle sizes.
\end{abstract}

Keywords: 55\%Al-Zn alloy coating; Spangle size; Corrosion resistance; Formability; Paintability

\section{FULL TEXT}

(C) 2018 The Authors. Published by ESG (www.electrochemsci.org). This article is an open access article distributed under the terms and conditions of the Creative Commons Attribution license (http://creativecommons.org/licenses/by/4.0/). 